\title{
$\Lambda$ crônica de Lulu Darola: a cidade de Salvador e o projeto de modernização
}

Nlana Oliveira Freitas El Fahl (FTC)

A coluna "Cantando e Rindo" foi publicada no jornal $A$ Tarde, entre os anos de 1891 e 1919. Sua duração coincide, portanto, com o período de ebulição que Salvador viveu diante dos vários acontecimentos que agitaram o país entre o final de um século e o início de outro. Dentre esses eventos, talvez o de maior relevância tenha sido a proclamação da República, em 1889, que impulsionou o pensamento civilizatório que revestia o país nas primeiras décadas do século XX. O novo regime trazia consigo os ideais de mudança, já que uma das máximas da modernização era justamente romper com o passado colonial.

Lulu Parola registra em suas crônicas toda essa fase de transição que representou a instauração de um novo pensamento, embalado pelo desejo de elevar Salvador à categoria de cidade moderna. Sobre a participação do cronista como testemunha desse processo histórico, destaca Pedro Calmon:

A história daquele amplo período da evolução da cidade, dos começos dramáticos da República a 1912, quando a engenharia do progresso se pôs a remodelar a velha Bahia, disfarçando-lhe com as novas ruas as rugas irreparáveis - toda a história da Bahia nos 29 anos em que trovou Aloísio de Carvalho, cabe nos seis milheiros de sua versificação jovial.(CALMON, 1966)

A observação de Pedro Calmon ratifica o caráter documental da atividade do cronista, que, através da sua coluna, redimensionava o fato histórico fazendo uso da propriedade artística das palavras. Numa espécie de jogo de interpretação e reinterpretação, ele recebia o fato e reelaborava-o de forma estética. 
A afeição do cronista pela sua cidade é evidente em toda a sua longa produção, desde o seu primeiro texto publicado em "Cantando e Rindo" (31-10-1891), no qual lamenta a sujeira de sua Salvador tricentenária, chamando-a de Ciscopólis, até a sua última crônica, publicada no jornal $A$ Tarde, em que lamenta a decadência dos costumes, comparando a sua própria decrepitude com a de Salvador (19-01-1942) ${ }^{1}$.

A leitura atenta de sua coluna nos possibilita perceber as várias transformações que Salvador sofrera nas duas primeiras décadas do novo século. Todo o frêmito vivido nesses anos agitados pelos ideais de modernização foi narrado pelo cronista baiano.

O espírito do lema "Bahia Civiliza-se" que dominava a sociedade soteropolitana já se fazia sentir antes mesmo do primeiro Governo J. J. Seabra (1912-1916), pois, nos primeiros anos do século, a chegada do automóvel (1901), da eletricidade (1903), do bonde elétrico (1905), da rede de esgotos (1905) imprimia uma atmosfera progressista na cidade.

Em crônica publicada em 1907, Lulu Parola apresenta alguns indícios das mudanças pelas quais Salvador passava, bem como algumas passagens significativas daqueles tempos de progresso em curso. Sobre a tradicional festa popular da "Segundafeira do Bomfim”, em crônica de 21/01/1907, de n. ${ }^{\circ}$ 3.381, ele afirma:

Hoje, por toda cidade

São fios que fazem gosto.

É tudo eletricidade,

Até no botar do imposto!

Miudinho!....amba, morena!

Compadre, passe o caneco!

$\mathrm{Na}$ rua grande e pequena,

Em todas corre o leleco!

O esgoto serve somente

Para a rua esburacar...

Aí seu doutor intendente!

Não precisa mais calçar!

Querem limpar-nos da peste,

Sem se limpar a cidade!...

Compadre, o caneco empreste,

Para dar imunidade!

34 - Légun \& mein: Rrvista de hitpratura e Divirsidadr Culupral, v. 6, no 4, 2008 
Nas passagens há referências diretas a elementos que representam as transformações do cenário urbano, como a instalação de fios elétricos atrelados à cobrança de impostos, as mudanças no sistema de transportes ocasionadas pela chegada do bonde elétrico, apelidado pelos passageiros de leleco ${ }^{2}$. O cronista refere-se também às obras de saneamento que esburacavam a cidade e ao pensamento higienista que buscava melhorar a saúde da população, através de intervenções no seu comportamento ${ }^{3}$.

Como podemos perceber, Salvador na primeira década do século era movimentada por uma série de acontecimentos que modificavam a sua paisagem. Esse ritmo de mudanças iria acentuar-se vertiginosamente a partir da gestão de J. J. Seabra. O governo seabrista realizou, na capital baiana, profundas modificações, através de diversas reformas efetuadas na arquitetura e nos costumes soteropolitanos, na esteira da influência das obras então realizadas na cidade do Rio de Janeiro. Sobre os encaminhamentos seabristas, afirma Rinaldo Leite:

Se o Rio de Janeiro já havia conhecido, ainda no princípio do século, a importância da atividade modernizadora; se São Paulo por transformações progressistas animadoras; se, de um modo geral, as capitais do Sul e mesmo algumas do Norte se metiam nos percursos da civilização, somente em 1912, Salvador conheceu a oportunidade, como nunca conhecera antes, de seguir as mesmas trilhas. A ascensão de J.J. Seabra ao governo do Estado, com seus projetos modernizadores da cidade, permitiu que se vislumbrasse uma nova possibilidade, dando ele início a várias obras de remodelamento. Os melhoramentos físicos, motor inicial de uma série de transformações que deveriam processar-se na cidade, estenderiam-se, paulatina e concomitantemente, para os serviços urbanos, a assistência pública, os hábitos e costumes da população, que também, seriam melhorados. (LEITE, 1996, p. 52)

Rinaldo Leite esclarece de forma ampla todas as posturas que deveriam ser adotadas para que as reformas civilizatórias transcorressem com sucesso. Como pontua o historiador, as obras físicas eram apenas uma das atitudes que direcionava o projeto seabrista. Elas teriam que ser acompanhadas de várias outras condutas que reforçavam os objetivos modernizantes, como, por exemplo, as mudanças de hábitos e costumes da sociedade, um dos emblemas do processo restaurador.

Lulu Parola, espectador privilegiado desse processo, registrará em suas crônicas diversas nuanças da administração seabrista, cujo maior ideal era colocar Salvador entre as capitais civilizadas da nação, sendo o Rio de Janeiro o principal espelho a se mirar. 
$\mathrm{Na}$ medida em que Seabra desenvolvia o seu projeto restaurador, o cronista Lulu ressignificava suas ações através de suas inconfundíveis parolas. Enquanto o primeiro demolia, construía e reconstruía, o segundo lia, interpretava e escrevia a cidade.

De forma geral, Salvador, segundo os ideais da época, precisava de obras que reformassem a paisagem urbana e de posturas que redimensionassem os costumes da população, então considerados atrasados e coloniais. Fernando da Rocha Peres no capítulo "Esse Progresso Demolidor", do livro Memória da Sé (1999, p. 42), ao referirse ao período em questão afirma que "a poesia escrita por Aloisio de Carvalho, o satírico Lulu Parola, será posta a serviço da causa reformista, dando um toque de humor e crítica aos acontecimentos”. Em seguida, o ensaísta cita algumas passagens do autor que justificam a afirmativa. Entre elas vale destacar as seguintes, publicadas, respectivamente, em 20/04/1912 e 14/05/1912, portanto no princípio do mandato de Seabra:

I

Reforma de costumes... É, de certo, Muito mais necessária que a das ruas...

Em avenidas, fica tudo aberto,

Quando, ó Progresso, em tudo mais jejuas.

II

Sim! Desta vez parece que a Mulata

Toma vergonha mesmo, e que endireita!...

Vejo que da toilette agora trata,

Como vaidosa dama que se enfeita!...

O comentário de Rocha Peres captura com eficiência a participação de Lulu Parola nos eventos reformistas. Os seus textos sobre o período sabem aplaudir, mas também sabem criticar, quando se faz necessário, sempre com suas notas de humor.

A primeira passagem selecionada por Rocha Peres delineia claramente os objetivos das reformas. As obras físicas eram importantes, mas a reforma de costumes representava uma tarefa muito mais difícil, pois abrir avenidas em nada se comparava a combater uma cultura solidificada por aproximadamente quatro séculos: (Quando, ó Progresso, em tudo mais jejuas.). 
Já no segundo exemplo, percebemos, através da seleção de palavras usadas pelo autor, uma evidente oposição entre o passado de Salvador, personificada na figura da mulata, e o que o progresso lhe traria. Através do termo toilette, fica claro o processo de europeização que as reformas objetivavam, uma vez que a mulata havia de se transformar em vaidosa dama. Assim, como observou Pedro Calmon, as rugas da cidade deveriam ser apagadas.

No texto também aparece, através do recurso da personificação, a cidade-mulher. Salvador é a mulata que se enfeita. As obras reformistas funcionam como a maquiagem dessa mulher-cidade, que se remodelava como uma dama parisiense.

Em 1912, primeiro ano da gestão Seabra, o Jornal de Notícias organizou uma enquete para os seus leitores na qual perguntava "De que é que mais precisa a cidade?”. O jornal recebeu diversas colaborações com as mais variadas respostas, entre elas as sugestões que mais se repetiam referiam-se a saneamento geral e estético e a inserção de arquiteturas modernas, o que confirma o envolvimento da sociedade com o ideário das reformas. Para registrar esse momento, Lulu Parola publicou o seguinte texto:

\section{DE QUE É QUE MAIS PRECISA A CIDADE? \\ $20 / 06 / 1912-n^{\circ} .4 .940$}

Eu vivo há três dia matutando

De que é que essa cidade mais precisa...

E por mais que umas coisas vá cortando,

Não posso tomar pé na pesquisa!

Menos pedra-navalha, onde se pisa?

Relógio sempre certo, e sempre andando ?

Água, luz, instrução ?... Não se organiza

A lista do que seja mais urgente;

Pois a cidade tantas falta sente,

Que ninguém chega ao fim - fazendo estudo...

Do que deva em primeiro ser tratado

Não se pode dizer... Está provado

Que em primeiro lugar... figura tudo. 
Em forma de soneto, o autor expõe a atmosfera do período em que a urgência por mudanças era manifestada de forma latente. A lista de exigências relacionadas na crônica exibe as carências da cidade, desde a limpeza, até a ausência de pavimentação ${ }^{4}$. Na conclusão, o autor generaliza as faltas da cidade. Em resumo, Salvador precisa de tudo (Que em primeiro lugar... figura tudo).

Nesta parola, o cronista revela o seu lado de cidadão de sua urbe, que também vive e participa dos eventos de sua terra. Lulu Parola, ao responder a enquete do jornal, se equipara aos demais moradores de Salvador que estavam atentos ao processo modernizador. Como porta-voz da cidade, ele opina como mais um soteropolitano que se interessa pelo que ocorre na sua cidade, pois o cronista também respira a poeira dos escombros.

Em 1913, segundo ano da administração de J. J. Seabra, Salvador já se sentia revirada pelo andamento das reformas. Algumas intervenções já eram nítidas, além de tantas outras que estavam em andamento. Lulu Parola continua a sua atividade de mestre de obras e letras, atento às modificações, como podemos perceber nos trechos abaixo:

\section{A TRADICIONAL SEGUNDA-FEIRA DO BOMFIM, DA GRANDE FOLGANÇA POPULAR NO CAVAQUINHO E NO SAMBA $20 / 011913-n^{\circ} .5112$}

As ruas vão se alargar

Não há ninguém que reprove:

É prá se ter onde andar, Depois dos tais otomove!...

(...)

Fon-fon, fon-fon, vai voando!

Não sei como é que ligeiro

Assim sem ser remanchando

Serve a quem é brasileiro!

(...)

Víspora é bom, também acho;

Mas só no alto somente!

Que se for aqui por baixo

A polícia agarra a gente! 
Os trechos acima acompanham, de fato, a evolução do projeto civilizatório de Salvador. O primeiro excerto contempla o automóvel, que simbolizava, justamente, um dos principais motivos para o alargamento das ruas. A cidade precisava adaptar-se para receber o novo meio de transporte que aportara na Bahia no início do século e alterava profundamente o cenário cotidiano. Os seus efeitos podem ser sutilmente vistos no segundo trecho, no qual o autor usa a onomatopéia (fon-fon) para representar o som das buzinas, sugerindo os seus efeitos sobre a sociedade.

O automóvel é o símbolo da rapidez e da tecnologia que a modernidade prometia. Além disso, portava o significado emblemático da diferença de classe social, já que possuir um automóvel no início do século XX era uma prerrogativa de um número bem restrito de baianos.

A terceira passagem dedica-se à outra face das reformas que buscava combater hábitos e práticas da população e que eram considerados anti-civilizados. A "víspora" era um tipo de jogo comum nas ruas de Salvador. Ora, os jogos populares eram considerados vícios que manchava a imagem de civilização, logo precisavam ser combatidos com energia.

As reformas adotavam um código de posturas que visava eliminar do cenário urbano práticas consideradas indignas daqueles novos tempos. Rinaldo Leite ainda nos informa sobre esses encaminhamentos das reformas:

Foi pensando em civilizar os costumes e as gentes da cidade que muitas das práticas populares e muitos dos usos que se faziam da rua, para o lazer ou para o trabalho, passaram a sofrer censuras e a conhecer formas de controle. Assim, a moralização e a reeducação das classes populares seriam defendidas com veemência, tendo por base os pressupostos idealizados pelas elites para a sociedade brasileira. (LEITE, 1996, p.111)

Alguns costumes da população eram considerados como males que atentavam contra a civilização. Dessa forma o jogo passa a ser perseguido, juntamente com outras atividades que propiciavam a reunião de pessoas "desocupadas" nas ruas. A capoeira, por exemplo, sofreu várias restrições nessa época, não só pelo seu lado de entretenimento popular, mas também pela sua ancestralidade africana, uma marca da história que, segundo o ideário civilizador da época, “deveria ser apagada”.

No ano seguinte, 1914, a sociedade baiana continuava assistindo à coreografia das picaretas seabristas. Nessa fase das obras, as dificuldades em realizar todas as modificações pretendidas começavam a aparecer. Mais uma vez, Lulu Parola não deixa escapar essa etapa do projeto: 


\section{A TRADICIONAL SEGUNDA-FEIRA DO BOMFIM, GRANDE DIA DO ZÉ-POVO \\ 19/01/1914 - n'. 5396}

- Seu doutô Seabra conta, Palavras bem garantidas, Que, saindo, deixa pronta

Meia dúzia de avenidas.

Eu creio no que ele diz;

Estou vendo o que já fez;

Mas não se faz no país

Nada sem o cobre inglês!

A primeira linha do texto, precedida de travessão, indica que essa fala circulava pela cidade. Isto é, Salvador discutia o andamento das obras e os obstáculos para a sua efetiva realização. $\mathrm{Na}$ segunda passagem, verificamos um desdobramento da primeira. O cronista confirma dar crédito a Seabra, porém, ironicamente, alude aos empréstimos vultosos realizados no período para que as reformas fossem viabilizadas. Esse fato realmente ocorreu, pois o Governo Seabra contraiu empréstimos em banco nacionais e estrangeiros, tendo, inclusive, a Assembléia Estadual autorizado um empréstimo de até dez milhões de libras esterlinas ${ }^{5}$.

O cronista, atento a todos os movimentos das reformas urbanas, estava sempre disposto a palpites sobre o projeto em curso, não se omitindo da sua função de narrar os eventos de sua terra. Aliás, algumas crônicas aqui citadas fazem parte da série "Segunda-feira do Bomfim", publicada em janeiro, durante o tradicional festejo popular. Numa primeira impressão, parece que o tema da crônica é o festejo em si, todavia logo percebemos que o autor realiza no texto uma espécie de balanço dos temas que aqueciam as discussões da cidade. E nessa fase as reformas eram o prato do dia.

Como já assinalado, as reformas não objetivavam somente obras de cunho físico, mas sobretudo medidas comportamentais que modificassem os hábitos da população considerados anti-civilizados. O pensamento intelectual defensor da regeneração via como uma ameaça ao progresso certos costumes que endossavam as nossas raízes africanas.

Para combater essa influência algumas medidas foram tomadas a fim de apagar das ruas diversos elementos da cultura afro-baiana, entre elas o hábito de vender 
comida nas ruas, o que para o ideal progressista era anti-higiênico e antiestético. A venda de acarajé e de outros quitutes do tabuleiro, uma das nossas maiores tradições culinárias, deveriam desaparecer do cenário civilizado do centro da cidade. Comer acarajé em público passou a ser sinônimo de atraso cultural. O cronista registra o assunto no seguinte texto:

\section{O ACARAJÉ, TÃO APIMENTADAMENTE}

GOSTOSO NA COZINHA AFRICANA

26/09/916- n. ${ }^{\circ} 6152$

Gosto do acarajé...Sou verdadeiro,

Muito embora isto pese

A quem só ama as coisas do estrangeiro...

Eu sei de muita gente

Que leva aos sete céus a mayonnaise,

Sendo possível que inda outros suba,

Por ter nome francês

E, portanto, se em vez

De ser acarajé, com o - é - aberto,

Escancaradamente,

Como bem termina a língua Yorubá,

Fosse o pitéu chamado acarajê,

Assim, nuns tons de boulevardier,

Aposto, dito e certo,

Que muita gente boa o comeria...

Porque gostoso ele é,

O tal apimentado acarajé,

Vindo, com os africanos, p'ra Bahia, E hoje já baiano!...

O texto citado é uma bela crônica de costumes sobre as mudanças de hábitos a que Salvador se via, de certa forma, obrigada a implantar a fim de se encaixar no figurino de "cidade civilizada". A reformulação do cenário urbano visava também a ações que levavam a um processo de desafricanização, que combatia as marcas do nosso passado colonial. Assim, os vestígios culturais africanos não poderiam coabitar com o modelo europeu de civilidade adotado na época. Sobre essa nuança das reformas afirma Raimundo Nonato Fonseca (2002): 
Velhas tradições ou costumes africanizados - o entrudo, a capoeira, os sambas, as festas de largo, o candomblé, os presentes para a mãe d'água, a venda de comidas nas ruas -, aos olhos dos reformadores, tudo o que contribuía, enfim, para "macular" a nossa "civilidade" e manter a cidade do Salvador semelhante a uma vila do interior da África deveria sofrer intervenção. (FONSECA, 2002, p.36)

A afirmação do historiador revela uma das faces das reformas, ou seja, o combate às marcas da africanidade na Bahia. Isso está representado na crônica de Lulu Parola, metonimicamente, pelo acarajé. O autor afirma, de forma bem humorada, que se o quitute se chamasse acarajê, ao modelo francês, não seria desprezado pelos baianos, mas que, o cronista, por ser verdadeiro, o aprecia.

No mesmo 1916, portanto último ano da gestão Seabra, com procedimento semelhante ao adotado na série "Segunda-feira do Bomfim", o autor retoma o tema civilizatório, ao escrever suas crônicas dedicadas às comemorações do Dois de Julho, série batizada de "Entrevista com o Caboclo":

INTERVIEW COM O TRADiCIONAL CABOCLO DO CARRO ALEGÓRICO DO DOIS DE JULHO, ONTEM SAÍDO À RUA, NA REVIVESCÊNCIA POPULAR DOS FESTEJOS DA GRANDE DATA BAIANA

$03 / 07 / 1916-n^{\circ} .6103$

Pois é isto, Caboclo! Aqui me tem

Você, para isto mesmo: uma entrevista,

Que há muitos anos era coisa feia

De pedir, quanto mais de conceder...

Mas hoje em dia está melhor a aldeia...

Pelo menos na vista...

$\mathrm{O}$ que eu quero saber

É, coisa muito simples, de corrida,

Que eu lhe direi de um salto:

Você gostou do asfalto?

Achou boa a Avenida?

Não pergunto à Cabocla, por baldio...

Ela gostou do asfalto com certeza,

Por que as mulheres gostam do macio,

Não só por natureza,

Mas também por amor dos sapatinhos...

E a entrevista continua na edição do dia seguinte: 
Continuação da entrevista com o tradicional Caboclo do Dois de Julho, SAÍDO ANTEONTEM À RUA

04/07/1916- no. 6104

Foi a primeira vez que você viu

Asfalto e Avenida:

E, com toda certeza, o que sentiu

Foi coisa indefinida...

Que me diz da surpresa

Da Igreja de São Pedro vir ao chão,

E acabar a estreiteza

Da garganta, que havia ali ao lado

Mãe da constipação ?!

Custou; Tudo, porém no mundo muda,

E cada vez o mundo é mais mudado!

Custou; mas custou menos que a Ajuda,

Que esta, sim, que foi coisa perigosa,

E cheguei a ver mesmo a coisa feia,

$\mathrm{Na}$ rua toda a aldeia

Acompanhando os santos lacrimosa.

Os exemplos acima são bastante significativos para a compreensão do estágio em que se encontrava as reformas urbanas em 1916. Os textos da série "Entrevista com o Caboclo" a cada ano apresentam ao casal de Caboclos as principais novidades de Salvador, já que os símbolos do civismo baiano só saem às ruas uma vez por ano. Usando esse hábil recurso de narrar as novidades, o cronista desfia os eventos ligados às mudanças regeneradoras da cidade.

No primeiro texto temos algumas referências importantes para o processo em curso. O autor utiliza sempre a ironia ao tratar da situação da "grande aldeia", uma das epítomes que ele usa para falar de Salvador. Essa denominação é bem sagaz, já que reúne as antíteses atribuídas à cidade, ao mesmo tempo vista como grande aldeia (cidade civilizada), mas também provinciana (aldeia).

O cronista critica sutilmente as "melhorias" de Salvador, já que a cidade está melhor "pelo menos, na vista". Ele prossegue falando do asfalto, da avenida, enfim, das grandes atrações da cidade civilizada, mas conclui alfinetando o processo modernizador, quando se refere às "pedrinhas agudas como espinhos,/ De que há ainda fartura a Bahia", existentes em regiões distantes do centro remodelado. 
No segundo texto, continuação do primeiro, publicado um dia depois, o cronista volta ao tema, pois não pode colocar o casal Caboclo a par de todas as novidades em apenas uma crônica. Ao persistir na missão de atualizar os emblemas cívicos da cidade, ele toca em uma das questões mais polêmicas do período. Trata-se da derrubada de igrejas que estavam localizadas em posições prejudiciais ao avanço do progresso, segundo o pensamento oficial.

De fato, a Igreja de São Pedro foi derrubada para a facilitar a construção da Avenida Sete de Setembro. A obra, símbolo da gestão Seabrista, tinha por modelo a Avenida Rio Branco do Rio de Janeiro. Juntamente com o templo, vieram ao ao chão algumas ruas adjacentes, as casas contíguas, e o Beco do Vigário, a tal garganta "Mãe da Constipação" citada no texto. Essa passagem exemplifica o impacto do ideal higienista que motivava as reformas, segundo o qual as ruas precisavam ser mais largas também por motivos de saúde pública.

A segunda demolição citada na crônica, a da Igreja da Ajuda, constituiu-se em umas das principais polêmicas que existiu em torno das reformas. "Que esta sim, foi coisa perigosa." A sua demolição enfrentou forte oposição de uma parcela da sociedade que defendia o seu valor histórico. Apesar da campanha, o monumnento sucumbiu às necessidades urbanísticas, em 1912. Suas imagens foram transferidas para a Igreja da V. O. Terceira de São Domingos, em comovente procissão acompanhada por populares. "Na rua toda a aldeia, acompanhado os santos lacrimosa".

A polêmica em torno da derrubada do templo inflamou as discussões sobre a necessidade das intervenções urbanísticas. Estas, se por um lado beneficiava o progresso, por outro comprometia as tradições. O cronista contempla mais uma vez essa polêmica na seguinte crônica:

Em razão de ir ser demolida a secular Igreja de N. Senhora da Ajuda, para a construção de uma avenida, foram ontem mudadas para a Igreja de São Domingos as respectivas imagens, uma procissão em que, na maior ordem, tomaram parte milhares de pessoas.

19/08/1912 - no. 4987

E lá se vai a procissão imensa

Que da capela secular da Ajuda,

Cumprindo do Progresso uma sentença,

Os inquilinos dos altares muda!

44 - Lejgun \& mein: Revista de litrpatura e Diversidadr Cultural, v. 6, no 4, 2008 
Gente menor, da média, da graúda,

Tudo ali vai, sentindo a mesma crença!...

Mesmo sendo no atraso cabeçuda,

Cede, prá não fazer a Deus ofensa!

Ei-lo solene o préstito, que avança,

O coração da gente emocionando,

Porque sempre comove uma mudança!...

Que belo quadro tenho n'alma impresso:

Um povo inteiro em procissão levando

$\mathrm{Na}$ crença em Deus a fé no seu Progresso!

Essa página é uma das mais representativas da produção do cronista Lulu Parola sobre o período. E devemos observar que sua data de produção situa-se no primeiro ano da gestão reformista de J. J. Seabra. O cronista soube captar com sensibilidade os acontecimentos que agitavam sua Salvador, quando a velha Cidade da Bahia se via atravessada pela lógica e pelos excessos dos ideais reformistas.

A questão em torno da Igreja da Ajuda revela bem a luta entre as tradições e o progresso. A tradição religiosa da cidade tinha que ceder espaço para o projeto progressista dos políticos, higienizadores e urbanístas. Segundo os ideais regeneradores, isso significava que a cidade precisava agora mais de avenidas do que de templos católicos. E a comoção da cidade ("Gente menor, da média e da graúda") refletia que a população não comungava com todas as demandas e urgências modernizadoras. Romper com os hábitos tricentenários era uma tarefa árdua para a cidade, que agora sentia que as picaretas seabristas não entoavam apenas a melodia do progresso, mas também o ruído abafado da queda das tradições.

Coube a Lulu Parola, cronista de Salvador, narrador do cotidiano de sua terra, observar, capturar e ressignificar em suas crônicas cada movimento do canteiro de obras no qual se transformou a velha cidade da Bahia, naqueles agitados anos da segunda década do século XX. Revirando a poeira dos escombros, o autor soube registrar cada etapa das reformas e os desdobramentos que causavam aos moradores de Salvador. Agindo como mestre de obras e de letras, o autor também reconstruía Salvador através de sua pena irônica e risonha.

Se cabe ao cronista o papel de ser um historiador do cotidiano, Aloísio de Carvalho, através de seu pseudônimo ilustre, Lulu Parola, cumpriu sua função de inscre- 
ver no livro de registro da cidade de Salvador suas páginas repletas de memórias, reflexões e risos sobre o período conhecido por "Bahia Civiliza-se!".

Os textos aqui mencionados e muitas outras parolas de Lulu constituem-se como um painel que apresenta uma Salvador que hoje pode ser reconstituída, graças à agudeza do cronista que cantou e riu os motes de sua "grande aldeia".

\section{$\operatorname{son}$}

\section{NOTAS}

$1 \mathrm{O}$ cronista falece em fevereiro de 1966.

2 Inaugurado para o tráfego da cidade alta em 25 de julho de 1905, servindo em primeiro lugar o Rio Vermelho, segundo Antonio Viana em nota explicativa dessa mesma crônica.

3 Os populares traziam um caneco preso à cintura para suas necessidades fisiológicas, fato que precisava ser combatido em nome da saúde pública.

4 As pedras navalhas citadas no texto são uma referência aos seixos que machucavam os pés da população, o asfalto, em algumas áreas, viria a amenizar o problema.

5 Luiz Henrique Dias Tavares reafirma os valores em questão no seu livro História da Babia.

\section{REFERÊNCIAS}

CALMON, Pedro. Edição comemorativa do centenário de Lulu Parola. Jornal A Tarde, 27-03-1966.

CARVALHO, Aloísio Lopes de. Cantando e Rindo - Coletânea de Versos de Lulu Parola. Salvador: Publicação da Diretoria do Arquivo, Divulgação e Estatística da Prefeitura Municipal, 1952.

FONSECA, Raimundo Nonato da Silva. "Fazendo fita": cinematógrafo, cotidiano e imaginário em Salvador, 18971930. Salvador: EDUFBA, 2002.

LEITE, Rinaldo. E a Babia Civiliza-se: ideais de civilização e cenas de anticivilidade em um contexto de modernização urbana, Salvador, 1912-1916.. Dissertação (Mestrado em História) - Faculdade de Filosofia e Ciências Humanas, UFBA, Salvador: 1996.

PERES, Fernando da Rocha. Memória da Sé. Salvador: EDUFBA,1996. 
A crônica de Lulu Parola: a cidade de Salvador e o projeto de modernização Lulu Parola's chronicles: the city of Salvador and the modernization project

\section{RESUMO}

O presente artigo analisa parte da produção do cronista baiano Lulu Parola, pseudônimo do jornalista Aloísio de Carvalho (1866-1942). Este trabalho tem a intenção de deter-se sobre os textos do autor produzidos à luz das reformas urbanas realizadas em Salvador no início do século XX, observando como tal evento histórico motivou a escrita do autor.

Palavras-Chave: Lulu Parola - Reformas urbanas - Salvador

\section{ABSTRACT}

This article analyzes part of the production of Lulu Parola, journalist whose real name was Aloísiso de Carvalho (1866-1942). The intention is to read the author's texts under the light of the urban reforms made in Salvador in the beginning of the XX century, considering how these historical events motivated Carvalho's writing.

Keywords: Lulu Parola - Urban reforms - City of Salvador

Recebido: $18 / 07 / 2007$

Aprovado: $12 / 03 / 2008$

Alana de Oliveira Freitas E1 Fahl é mestre em Literatura e Diversidade Cultural pela Universidade Estadual de Feira de Santana. Doutoranda em Teorias e Críticas da Literatura e da Cultura na UFBA É professora substituta da Universidade Estadual de Feira de Santana, lecionando Literatura Portuguesa, e professora da Faculdade de Tecnologia e Ciências de Feira de Santana. Tem artigos publicados nas revistas Latitudes: cabiers lusophones e Qvinto Império e em jornais baianos. 